\title{
Economia criativa e desenvolvimento: uma análise do desenho da política pública de São José dos Campos (SP)
}

\author{
Economía creativa y desarrollo: un análisis del diseño de políticas en São \\ José dos Campos (SP)
}

\section{Creative economy and development: an analysis of the policy design in São José dos Campos (SP)}

\author{
Rafael Barbosa de Aguiar ${ }^{a}$ [을 , Luciana Leite Lima ${ }^{b}$ \\ ${ }^{a}$ Universidade Federal do Rio Grande do Sul, Porto Alegre/RS, Brasil. Doutorando e Mestre em Políticas Públicas pela Universidade \\ Federal do Rio Grande do Sul (UFRGS/RS).rafaelba@yahoo.com.br \\ ${ }^{b}$ Professora do Programa de Pós-Graduação em Políticas Públicas e do Departamento de Sociologia da Universidade Federal do Rio \\ Grande do Sul, Porto Alegre/RS, Brasil.Doutora em Ciências Sociais (Unicamp) e Mestre em Sociologia (UFRGS). lucianaleiteli- \\ ma@gmail.com
}

Resumo: Este trabalho apresenta uma análise do desenho da política pública de economia criativa no município de São José dos Campos à luz de uma perspectiva de desenvolvimento. O objetivo foi verificar se havia a promoção do desenvolvimento multidimensional e a endogeneização do conceito em relação ao contexto local. Esta é uma pesquisa exploratória e descritiva, na qual se adotou o estudo de caso e a pesquisa documental, tendo sido realizada uma análise de conteúdo a partir de dados secundários. Como resultado, constatamos que as perspectivas de desenvolvimento que prevalecem no desenho da política são a multidimensional (normas) e unidimensional, focada apenas na dimensão econômica (ações), comprometendo a promoção do desenvolvimento de forma ampla. Além disso, se por um lado encontramos uma pluralidade de atores previstos nas políticas, por outro não identificamos as formas de manifestação dessa heterogeneidade nas decisões, ainda, a ausência de transparência reforça essa dinâmica.

Palavras-chave: Desenho de Políticas Públicas; Fatores Estruturantes; Economia Criativa; Desenvolvimento.

Resumen: Este trabajo presenta un análisis del diseño de la política pública de economía creativa en la ciudad de São José dos Campos (SP) a la luz de una perspectiva de desarrollo. El objetivo fue verificar si estas políticas promovieron el desarrollo multidimensional y la endogeneización del concepto en relación al contexto local. Se trata de una investigación exploratoria y descriptiva, en la que adoptamos el estudio de caso y la investigación documental. Realizamos un análisis

Como citar o artigo: AGUIAR, R.B.; LIMA, L.L. Economia criativa e desenvolvimento: uma análise do desenho da política pública de São José dos Campos (SP). Revista de Ciências Humanas, Florianópolis, v. 54, 2020 DOI: 10.5007/2178-4582.2020.e74029 você pode compartilhar, adaptar, para qualquer fim, desde que atribua a autoria da obra, forneça um link para a licença, e indicar se foram feitas alterações. 
de contenido de datos secundarios. Como resultado, encontramos que las perspectivas de desarrollo que prevalecen en el diseño de políticas son multidimensionales (normas) y unidimensionales, enfocadas solo en la dimensión económica (acciones), comprometiendo la promoción del desarrollo de manera amplia. Además, si por un lado encontramos una pluralidad de actores previstos en las políticas, por otro lado no identificamos las formas en que esta heterogeneidad se manifiesta en las decisiones, pero la falta de transparencia refuerza esta dinámica.

Palabras clave: Diseño de la Política Pública; Factores Estructurantes; Economía Creativa; Desarrollo.

\begin{abstract}
This paper presents an analysis of public policy design focused on the creative economy of São José dos Campos (SP) in the light of a development perspective. The objective was to verify if these policies promoted multidimensional development and the concept's endogenization in relation to the local context. This is exploratory and descriptive research, in which we adopted the case study and the documentary research. We conducted a content analysis of secondary data. As a result, we found that the development perspective that prevails in policy design are multidimensional (norms) and one-dimensional, focused only on the economic dimension (actions), compromising the promotion of development in a broad way. Moreover, if, on the one hand, we found a plurality of actors, on the other hand, we did not identify the forms of manifestation of heterogeneity in decisions, along with this, the absence of transparency reinforces this dynamic.
\end{abstract}

Keywords: Policy Design; Structuring Factors; Creative Economy; Development.

\title{
INTRODUÇÃO
}

A economia criativa pode ser definida como o conjunto de atividades econômicas relacionadas à produção e distribuição de bens e serviços que utilizam a criatividade e as habilidades dos indivíduos ou grupos como insumos primários (BRASIL, 2012; REIS, 2008; UNITED NATIONS CONFERENCE ON TRADE AND DEVELOPMENT [UNCTAD], 2010). Tal conceito, bem como seu estabelecimento como uma disciplina de estudo, ganhou expressão e relevância a partir da década de 2000. Na esteira desse movimento, se tornou também, um campo de intervenção, como forma de gerar e incrementar retornos sociais a partir do desenvolvimento da indústria criativa.

Desde seu surgimento, tal indústria tem se mostrado cada vez mais proeminente para as economias do Brasil e do mundo. De acordo com a Federação das Indústrias do Estado do Rio de Janeiro (FIRJAN, 2016a), o PIB criativo estimado do Brasil para o ano de 2015 foi de R \$ 155,6 bilhões, tendo crescido aproximadamente $80 \%$ em 11 anos, passando de 2,04\% em 2004 para 2,64\% em 2015 do PIB total brasileiro. O destaque do setor na economia influenciou a criação de capacidades estatais, o que se expressou na constituição da Secretaria de Economia Criativa no Ministério da Cultura em 2012 (OLIVEIRA; ARAÚJO; SILVA, 2013).

Esse movimento marcou o ingresso da economia criativa nas agendas governamentais de políticas públicas no país. Como desdobramento, foram criadas estruturas e capacidades correspondentes nas demais esferas. Por exemplo, a cidade de São Paulo instituiu um polo de economia criativa (SÃO PAULO, 2014) e Porto Alegre formulou um plano municipal de economia criativa (PORTO ALEGRE, 2014). Portanto, temos um setor econômico emergente e um direcionamento de políticas públicas que tentam influenciar sua estrutura e dinâmica.

O potencial de crescimento econômico da economia criativa e as ações desenvolvidas pela esfera pública para alavancar esse setor levam nossa atenção para as políticas públicas de fomento e para suas pretensões de contribuir para o desenvolvimento social. Nesse sentido, este trabalho apresenta uma análise do desenho de políticas públicas voltadas à economia criativa a partir de um enfoque de desenvolvimento.

Trabalhamos, assim, com a perspectiva do desenho de políticas, que propõem analisá-las a partir de seu conteúdo, dos elementos que compõem sua estrutura. Também, acionamos a perspectiva do desenvolvimento endógeno, a partir da qual foram elaboradas as categorias analíticas. A partir daí, indagamos: o desenho da política pública de economia criativa promove o desenvolvimento multidimensional e a endogeneização do conceito em relação ao contexto local? Como contexto empírico, trabalhamos com as políticas do município de São José dos Campos (SP), em virtude de seu prota- 
gonismo estadual como polo de economia criativa, justificada pela extensa presença de institutos de pesquisa, instituições de ensino superior, empresas e etc., além de empregar um grande número de talentos criativos, o que proporciona um campo fértil para o estudo.

Muitos estudos têm enfocado o impacto da economia criativa no crescimento econômico (BRASIL, 2012; DEPARTMENT OF CULTURE, MEDIA AND SPORT [DCSM], 2001; FIRJAN, 2016a), esta pesquisa pretende contribuir direcionando o olhar para o desenho das políticas, que, no nível municipal, tentam fomentar essa indústria; ou seja, atenta-se para a dimensão dos processos na busca por compreender os resultados (desenvolvimento). Assim sendo, pretende-se estimular pesquisas e praticas de desenho de políticas públicas, dado que é crucial repensar o âmbito de ação dos agentes públicos para a construção e implementação de políticas públicas que possam atingir as finalidades pretendidas (OHLWEILER, 2007).

$\mathrm{O}$ artigo está divido em quarto seções além desta introdução e da conclusão. Na primeira, apresentamos o referencial teórico sobre policy design e desenvolvimento endógeno que embasam o estudo. $\mathrm{Na}$ segunda, explanamos sobre o esquema de análise, na terceira apresentamos os procedimentos metodológicos, além do critério de seleção e informações inicias sobre o caso estudado; e na quarta trazemos a análise dos dados por meio da perspectiva de desenvolvimento e da endogeneidade que embasam o desenho da política pública de economia criativa de São José dos Campos, oferecendo, por último, um panorama do município.

\section{REFERENCIAL TEÓRICO}

POLICY DESIGN

O termo policy design passou a ser utilizado na policy analisis a partir da década de 1980 (COLEBATCH, 2018). Embora seja possível encontrar algumas variações nas definições, há grande equivalência entre elas. Por exemplo, Peters (2020) sustenta que desenhar uma política envolve reconhecer a existência de um problema público, tentar entender sua dinâmica e, a partir daí, delinear uma solução; já Linder e Peters (1990) destacam que o desenho tem a ver com boas ideias sobre o que é o problema e sobre como lidar com ele da melhor forma bem como com a escolha dos instrumentos e sua adequação aos contextos de ação; e Howlett, Mukherjee e Woo (2015) entendem que policy design envolve a tentativa deliberada de definir objetivos e conectá-los com instrumentos que possam cumpri-los.

O policy design é uma atividade realizada para formular opções de política com um olho voltado à eficácia de implementação (HOWLETT, 2020). Também envolve o esforço consciente de analistas e consultores para examinar, aprender, e aplicar lições de melhores práticas, tendo em mente os sucessos (ou fracassos) anteriores de políticas na elaboração alternativas para alcançar os objetivos e ambições governamentais (HOWLETT, 2020; HOWLETT; MUKHERJEE, 2017, 2018). O desenho é apresentado como um conjunto lógico de elementos de construção intencional, possuindo, dessa forma, finalidade explícita. Nessa acepção, Howlett e Mukherjee (2018) entendem que a efetividade é o propósito fundamental do desenho, isto é, a capacidade da política pública de atingir seus objetivos. Tais definições indicam duas preocupações do campo: promover políticas que enfrentem os problemas sociais que justificaram sua criação e qualificar o policymaking por meio da produção de conhecimento sobre os processos de desenho e da valorização do uso intensivo de conhecimento, característica que diferenciaria o design de outras formas de formulação (HOWLETT, 2020).

Essas ideias expõem um pressuposto que marca o desenvolvimento desse campo, e que assumimos neste trabalho: o de que políticas melhor desenhadas são mais prováveis de identificar e enfrentar problemas sociais, e servir ao bem comum, do que políticas mal desenhadas (HOWLETT; MUKHERJEE; WOO, 2015). Tal fundamento reconhece que os processos decisórios podem exibir diferentes graus de contingência e de racionalidade instrumental, nos quais as considerações de design podem estar mais ou menos presentes, (HOWLETT; MUKHERJEE, 2018; HOWLETT; MUKHERJEE; WOO, 2015) 
e que o desenho é afetado pelas características políticas, culturas organizacionais e pelas conexões com atores sociais (PETERS, 2020). Com efeito, Chindarkar, Howlett e Ramesh (2017) enfatizam que parte do desafio do policy design está em balancear objetivos técnicos e políticos.

\section{DESENVOLVIMENTO ENDÓGENO}

Dentro do longevo e diversificado campo de debate sobre desenvolvimento, mobilizaremos a literatura em desenvolvimento endógeno. Tal perspectiva foi engendrada ao longo dos anos 1980 e 1990 para lançar luz sobre as novas atribuições das cidades e regiões em um contexto de globalização e descentralização política, dando centralidade para as experiências de países latino-americanos e europeus de desenvolvimento tardio (BOISIER, 2005; COELHO, 2000; TAPIA, 2005; VÁZQUEZ BARQUERO, 2001; VITTE, 2006). A questão central aqui é compreender como as localidades respondem às demandas do contexto externo sem descuidar do propósito de promover a melhoria das condições locais.

Nesse recorte, entende-se que o desenvolvimento endógeno é um processo de crescimento e mudança estrutural, que se dá através do uso do potencial de desenvolvimento existente no território bem como da endogeneização de oportunidades externas, com o objetivo de melhorar o bem-estar da população (VÁZQUEZ BARQUERO, 2000). Um elemento importante nesta abordagem é a endogeneidade. Ela refere-se ao protagonismo do território e dos atores locais nos processos de desenvolvimento.

O território é entendido como um recorte definido, abrangendo aglomerados sociais que compartilham dadas características identitárias. Segundo Tirelli (2020, p. 246), o conceito de território pode ser tomado "como um fator explicativo dos processos que delimitam as possibilidades e os constrangimentos para os seus atores, contribuindo para as análises que objetivam compreender como as políticas públicas são implementadas e quais os efeitos que produzem nos diferentes locais".

Como decorrência da imbricação conceitual entre endogeneidade e território, teríamos um enfoque ascendente de desenvolvimento, no qual as iniciativas locais "aparecem como a forma que toma o desenvolvimento endógeno na prática” (VÁZQUEZ BARQUERO, 2007, p. 41, tradução nossa). Ou seja, o local pode ser identificado com o município, com o âmbito inframunicipal ou supramunicipal; bem como, com redes de empresas, comunidades específicas (por ex. quilombolas), até mesmo com um país ou um conjunto deles (DOCAMPO, 2007). Contudo, o município é comumente utilizado como um recorte privilegiado nos estudos porque corresponde a uma unidade administrativa e política bem delimitada espacialmente, com competências claras e capacidades de desenhar estratégias e mobilizar atores (BUARQUE, 1999; ALBUQUERQUE; ZAPATA, 2010).

A valorização da dinâmica territorial coloca foco no protagonismo da sociedade local e na pluralidade de atores que interagem neste espaço, influenciando e sendo influenciados pelos processos de mudança social. Estes elementos forjam o contorno multidimensional desta perspectiva de desenvolvimento, como vemos, por exemplo, na concepção proposta por Buarque (1999, p. 9):

\footnotetext{
desenvolvimento local é um processo endógeno registrado em pequenas unidades territoriais e agrupamentos humanos capaz de promover o dinamismo econômico e a melhoria da qualidade de vida da população. Representa uma singular transformação nas bases econômicas e na organização social em nível local, resultante da mobilização das energias da sociedade, explorando as suas capacidades e potencialidades específicas. Para ser um processo consistente e sustentável, o desenvolvimento deve elevar as oportunidades sociais e a viabilidade e competitividade da economia local, aumentando a renda e as formas de riqueza, ao mesmo tempo em que assegura a conservação dos recursos naturais.
}

Nesse sentido, o desenvolvimento endógeno seria uma estratégia que busca o progresso social e a sustentabilidade desse processo, percebendo o crescimento econômico e a distribuição de renda 
como dimensões de um mesmo fenômeno, uma vez que atores públicos e privados, quando decidem executar seus investimentos, eles o fazem, a fim de aumentar a produtividade e melhorar o bem-estar da sociedade. De forma relacionada, tal visão também estaria baseada na melhoria contínua dos recursos disponíveis, particularmente recursos naturais e do patrimônio histórico e cultural. Assim, perceber o desenvolvimento enquanto mudança social desejada permite conectá-lo com as políticas públicas, uma vez que elas conformariam meios para produzir tal mudança. Ainda, esse esquema pressupõe que o desenvolvimento é um objetivo que pode ser perseguido por meio de ações deliberadas (LIMA; D’ASCENZI, 2018).

Por fim, a luz deste referencial, assume-se que a capacidade das políticas públicas de promoverem mudanças sociais complexas depende da endogeneização dos elementos exógenos. Neste caso, o conceito de economia criativa. Assim, a seguir, apresentaremos as dimensões analíticas que serão utilizadas para analisar o desenho da política de economia criativa de São José dos Campos com o intuito de verificar as formas de apropriação local dos fatores exógenos como uma proxy da efetividade potencial em termos de desenvolvimento.

\section{ESQUEMA DE ANÁLISE}

O desenho de uma política pública é expresso por meio de sua estrutura normativa, isto é, as diversas normas que a apresentam, descrevem e orientam sua implementação. Nesse sentido, para analisar as políticas públicas voltadas à economia criativa foi delineada uma abordagem a partir do que se denominou fatores estruturantes, entendidos como um conjunto de normas, que configuram a estrutura normativa da política, ou seja, o seu desenho.

Neste estudo, o desenho da política em foco foi desmembrado nos seguintes fatores estruturantes: instrumentos de planejamento, incentivos ao setor, estrutura organizacional governamental e relações intergovernamentais.

Os instrumentos de planejamento são ferramentas normativas formais que orientam as escolhas de políticas públicas e visam aumentar as chances de atingir as finalidades pretendidas. Aqui podemos considerar: as iniciativas de economia criativa no Plano Plurianual (PPA) ${ }^{1}$, Plano de Economia Criativa, leis, decretos, portarias que regulamentam atividades de economia criativa, dentre outros. Por sua vez, os incentivos ao setor são todos os estímulos instituídos para alavancar a economia criativa. Neste caso podem ser analisadas leis, normas, portarias e decretos que estabeleçam diferentes tipos de incentivos ao desenvolvimento da indústria criativa, seja por meio de benefícios fiscais, de arranjos produtivos locais, redes, ecossistemas no geral etc. A estrutura organizacional governamental diz respeito à forma pela qual o governo está organizado em torno da divisão de atividades e recursos com fins de cumprir os planos de governos. Corresponde à existência (ou não) de órgãos gestores criados especialmente para implementar e monitorar a política de economia criativa, bem como seus objetivos e instrumentos, quais sejam: secretarias específicas, diretorias, espaços de concertação entre diversos atores. Deve-se ficar atento as estruturas intersetoriais, dada a natureza e as diversas finalidades que estas políticas podem atender. Por exemplo, podemos encontrar ações de economia criativa voltadas à promoção de artesanato regional, bem como à expansão da indústria 4.0. Por fim, as relações intergovernamentais são as formas pelas quais ocorrem as interações entre os entes federados, no sentido de cooperação e coordenação. Aqui se observa a existência de diferentes tipos de parcerias entre os governos para promover incentivos ao desenvolvimento da economia criativa.

Em nosso esquema, os fatores estruturantes, que representam o desenho da política, correspondem ao objeto de análise, cabe, agora, definir como serão analisados, isto é, quais são as dimensões analíti-

1 O PPA é um instrumento previsto no art. 165 da Constituição Federal destinado a organizar e viabilizar a ação pública, com vistas a cumprir os fundamentos e os objetivos da Administração. Por meio dele, é declarado o conjunto das políticas públicas do governo para um período de 4 anos e os caminhos trilhados para viabilizar as metas previstas (BRASIL, 2018). 
cas. Com base na literatura em desenvolvimento endógeno, delineamos duas categorias. A primeira é a perspectiva de desenvolvimento. Sua relevância deriva do fato de que o desenvolvimento é utilizado como justificativa para a elaboração de normativas de incentivo à economia criativa, e vinculado a ela pelas organizações que a difundem (DCSM, 2011; UNCTAD, 2010). Analisar tal perspectiva envolve identificar qual a ideia de desenvolvimento que está embasando as iniciativas: se uma abordagem multidimensional, que abarca diversas dimensões da sociabilidade ou mais restrita. Como se viu, a visão contemporânea de desenvolvimento enfatiza as interações entre múltiplos fatores sociais, assumindo a complexidade dos problemas públicos (HEIDEMANN, 2014; INGLEHART; WELZEL 2009; SEN, 2010). De outra forma, a perspectiva de desenvolvimento manuseada aqui sustenta que a multidimensionalidade é derivada da endogeneidade. Assim, os dois elementos são interdependentes e se reforçam.

A segunda categoria é a endogeneidade, relacionada a potencializar os atributos locais e melhorar as condições de vida da população. Essa ideia está no centro da abordagem do desenvolvimento endógeno. Tal categoria pode ser desmembrada nas dimensões inter-relacionadas: participação, normatividade e transparência (DAGNINO, 2002; LAVALLE; VOIGT; SERAFIM, 2016).

A participação, diz respeito à heterogeneidade de atores. Parte-se do pressuposto de que os problemas sociais decorrem de inúmeras variáveis, quanto maior a diversidade de atores participantes dos processos de desenho e implementação das políticas públicas, maior a capacidade de adaptação ao contexto e de mobilização de recursos e capacidades existentes (COMPTON; LUETJENS; HART, 2019; DAGNINO, 2002; LAVALLE; VOIGT; SERAFIM, 2016). Isso porque a pluralidade de atores oferece aos processos decisórios uma variedade de visões de mundo, informações e recursos, os quais possibilitam lidar com a complexidade dos problemas públicos. A normatividade, por sua vez, tange às formas por meio das quais a participação é propiciada, entendida como regras decisórias que garantem que aquela heterogeneidade protagonize a decisão (DAGNINO, 2002; LAVALLE; VOIGT; SERAFIM, 2016). Por fim, a transparência, que é alicerce do controle social, e condição para a participação e monitoramento da gestão pública (PLATT et al., 2007). Entende-se que ela não consiste apenas em informar a sociedade a respeito do que os governos planejam ou realizam e como o fazem, mas também em explicar sua atuação e avaliação quanto ao grau de influência da própria sociedade no processo de tomada de decisão. De acordo com Martins Júnior (2010, p. 23), “a transparência representa um ritual de passagem de um modelo de administração autoritária e burocrática à administração de serviço e participativa", neste novo enfoque a informação sobre todos os aspectos da Administração Pública é o pressuposto fundamental da participação, que é vital para o alcance da endogeneidade.

Para o presente estudo, os fatores estruturantes representam "o que" será analisado, enquanto as dimensões do desenvolvimento endógeno, “como", conforme representado na Figura 1.

Figura 1 - Representação sinóptica do modelo analítico

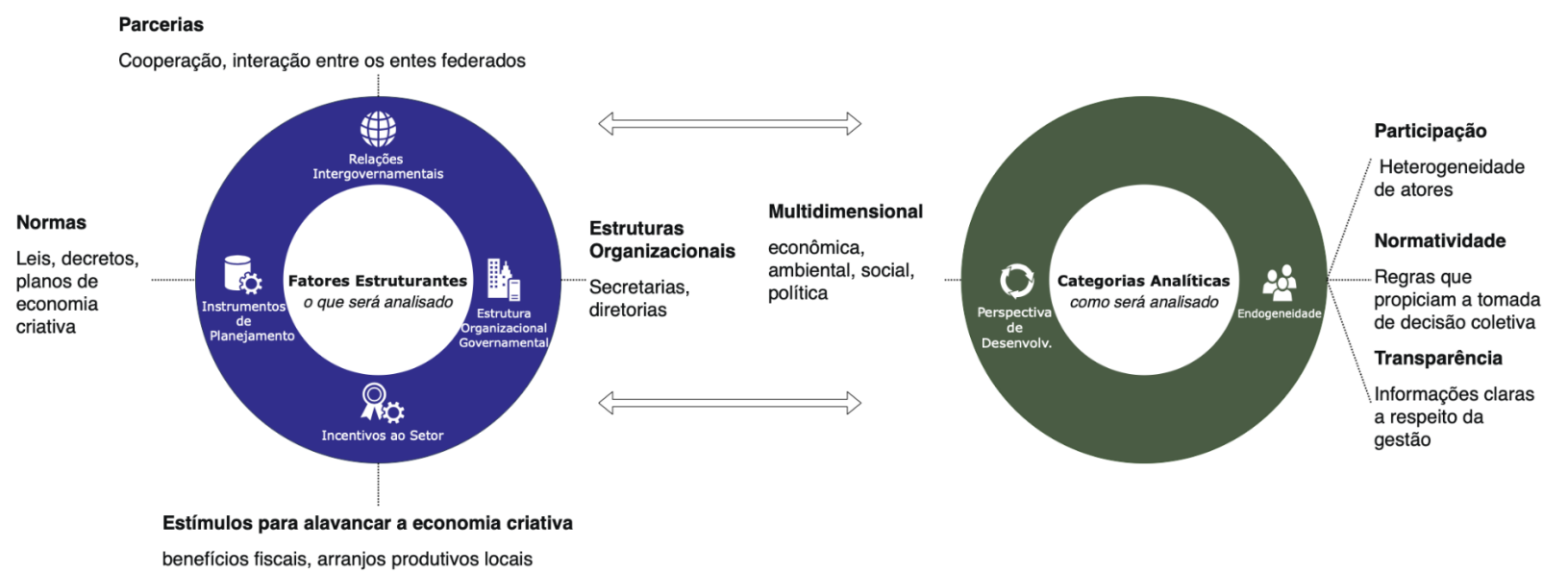

Fonte: Elaborada pelos autores. 
Enfim, assume-se que as categorias analíticas permitirão investigar se as políticas de economia criativa em foco são modeladas de forma a incorporar as características locais e direcionar-se para o desenvolvimento da comunidade. Isso se torna relevante uma vez que o conceito que embasa as políticas voltadas a essa indústria provém de contextos externos, e sua difusão se deu por meio da ação de organizações internacionais (DCSM, 2011; UNCTAD, 2010).

\section{PROCEDIMENTOS METODOLÓGICOS}

Esta é uma pesquisa exploratória porque pretende produzir informações sobre a política de economia criativa no município de São José dos Campos. E também é descritiva, uma vez que apresentará um retrato (ou uma exposição) dessa política pública a partir dos elementos de seu respectivo desenho. Para tanto, se adotou o estudo de caso e a pesquisa documental. Trabalhamos com dados secundários provenientes de leis, decretos, planos, programas, manuais e material informativo. Os dados foram coletados on-line nas páginas dos governos do estado, prefeitura, associações, fundações etc., e foram examinados por meio de análise de conteúdo (BARDIN, 2007), conforme as categorias do esquema de análise.

Com base no Índice de Criatividade das Cidades (ICC), criado pela Federação do Comércio de São Paulo (FECOMÉRCIO, 2012), selecionamos o município de São José dos Campos como caso de estudo. $\mathrm{O}$ índice ranqueou cinquenta cidades utilizando diversos subindicadores ${ }^{2,3}$, São José dos Campos apresentou ICC igual a 060,9, considerado de médio nível de criatividade (FECOMERCIO, 2012).

De acordo com o Instituto Brasileiro de Geografia e Estatística (2016), a população estimada no município é de 695.992, com uma população economicamente ativa de 336.282, sendo o Índice de Desenvolvimento Humano Municipal (IDHM) e Coeficiente de Gini no ano de 2010 de 0,807 e 0,550 , respectivamente. A taxa média de desemprego passou de $17,25 \%$, em 2000 , para $7,14 \%$, no ano de 2010 (IBGE, 2016). O município abriga diversas instituições de ensino ligadas à pesquisa e a tecnologia como o Instituto Tecnológico de Aeronáutica (ITA), Universidade Federal de São Paulo (UNIFESP), Faculdade de Tecnologia de São José dos Campos (FATEC), Departamento de Ciência e Tecnologia Aeroespacial (DCTA), Instituto Nacional de Pesquisas Espaciais (INPE), assim como é sede do Parque Tecnológico e de grandes empresas, a exemplo da Empresa Brasileira de Aeronáutica (EMBRAER).

Nesse contexto, o protagonismo de São José dos Campos na economia criativa se justifica pela vasta presença de institutos de pesquisa e instituições de ensino superior no município. Mais da metade dos talentos criativos da cidade atuam na área de $P \& D(55,3 \%)$, frente à cerca de $20 \%$ no total do estado paulistano (FIRJAN, 2016c). O número total de profissionais criativos na cidade é de aproximadamente 9.961, envolvendo as áreas de arquitetura, artes cênicas, audiovisual, biotecnologia, design, editorial, expressões culturais, moda, música, patrimônio e artes, P\&D, publicidade e TIC (FIRJAN, 2016b).

A economia criativa no município fica sob responsabilidade do Departamento de Programas Estratégicos da Secretaria de Inovação e Desenvolvimento Econômico. Tal estrutura foi instituída pela Lei $\mathrm{n}^{\circ} 9.495$ de 14 de fevereiro de 2017, para fomentar ações com fins de promover seu fortalecimento e, também, o espraiamento para outras áreas da indústria criativa, uma vez que o município

2 Indicador de Condições Econômicas que levou em consideração o PIB per capta, renda per capita, porcentagem do PIB de serviços e número de empresas por habitante; Indicador de Condições Sociais que teve como base número de estabelecimentos públicos de saúde, saneamento básico per capta e a proporção entre emprego total pela população; e Indicador de Criatividade no qual considerou o emprego criativo per capta e emprego super criativo per capta, para definir o nível de criatividade em cada uma das localidades.

3 Para cada subindicador, algumas variáveis são comparadas, e a maior pontuação em cada quesito passa a valer 100 pontos. A soma das pontuações por quesito dividida pelo número de quesitos resulta na pontuação geral do subíndice, que vai de 0 a 100. A soma de todos os quesitos (de todos os subindicadores) dividida pelo número total de quesitos resulta no indicador Geral - que a rigor acaba sendo uma média ponderada dos subindicadores (FECOMERCIO, 2012). 
se destacou frente a outros do estado de São Paulo, principalmente em P\&D (FIRJAN, 2016b, 2016c; SÃO JOSÉ DOS CAMPOS, 2017a).

Assim, percebe-se que a economia criativa faz parte da realidade de São José dos Campos, o que proporciona um campo fértil para o estudo. Cabe, então, analisar se as iniciativas empreendidas pelo município para promovê-la abarcam as diversas dimensões da sociabilidade e se estão relacionadas a potencializar os atributos locais e melhorar as condições de vida da população, nos conduzindo aos resultados e discussão.

\section{RESULTADOS E DISCUSSÃO}

Este subtópico visa apresentar os fatores estruturantes de políticas públicas de economia criativa encontrados em São José dos Campos (SP) possibilitando a análise de seus desenhos por meio das categorias analíticas. Como instrumento de planejamento foram localizados apenas os planos plurianuais, em incentivos ao setor, estão os benefícios fiscais e o fundo municipal de cultura. Já a estrutura organizacional governamental, conta com a secretaria municipal de inovação e desenvolvimento econômico e o sistema municipal de cultura; as relações intergovernamentais trouxeram, a nível federal, o plano da Secretaria da Economia Criativa e, a nível estadual, os programas fortalecimento da competitividade territorial e regional e fomento cultural e indústria criativa, apresentados na Figura 2.

Figura 2 - Fatores Estruturantes de Políticas Públicas do Município de São José dos Campos (SP)

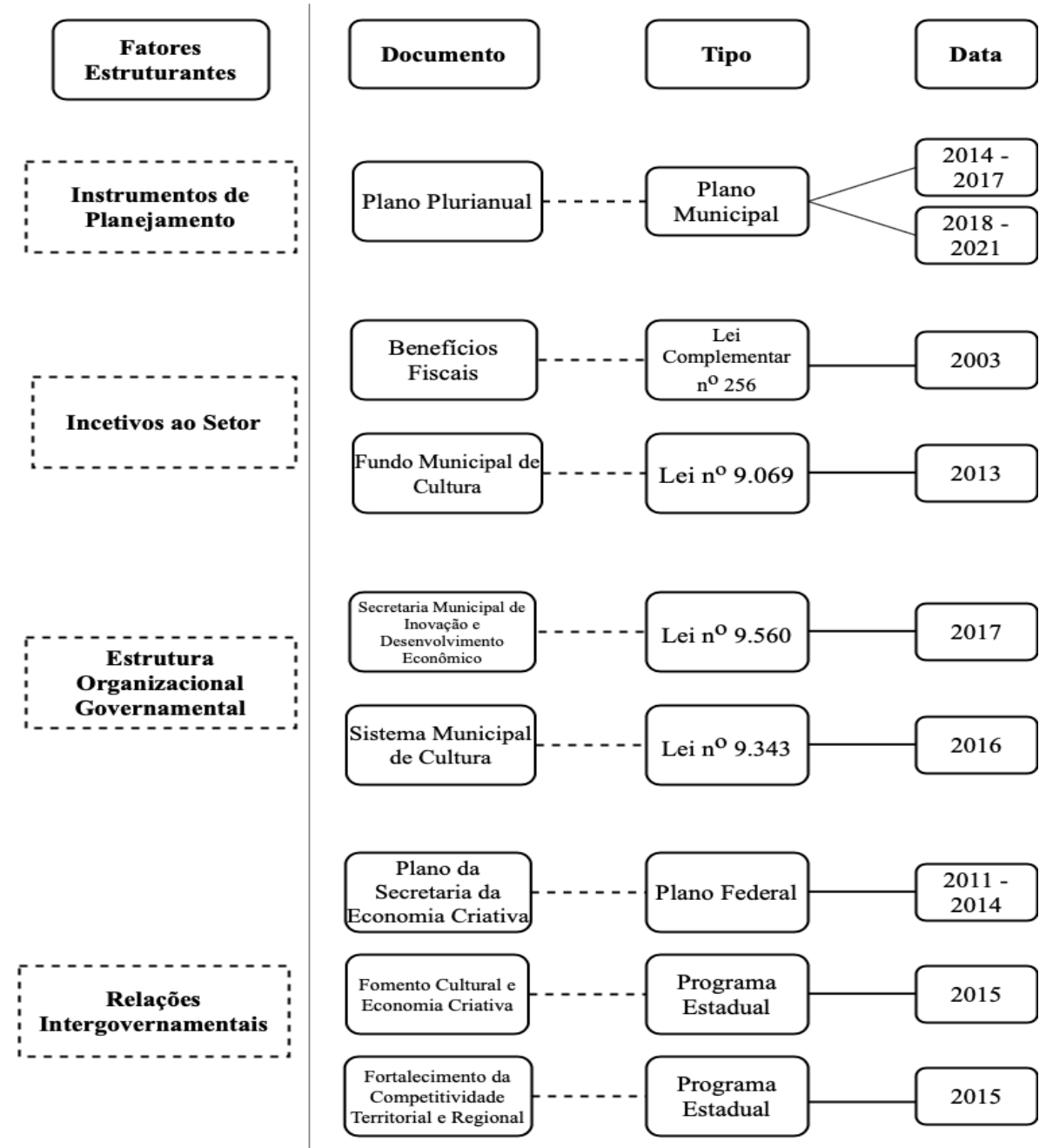

Fonte: Elaborado pelos autores com base nos dados de Brasil (2012), São José dos Campos (2003, 2013a, 2013b, 2016, 2017a, 2017b) e São Paulo (2015). 


\section{ANÁLISE POR MEIO DAS CATEGORIAS}

A análise por meio das categorias tem o intuito de evidenciar os campos de atuação das políticas públicas de economia criativa, aproximando da perspectiva de desenvolvimento e endogeneidade, esta subdivida em participação, normatividade e transparência, que os embasam e que os refletem.

\section{Perspectiva de Desenvolvimento}

Pretendemos aqui analisar a categoria denominada de perspectiva de desenvolvimento. Em outras palavras, buscamos identificar qual a ideia de desenvolvimento que está embasando as iniciativas voltadas à economia criativa no município de São José dos Campos. Isto é, nelas o desenvolvimento é entendido de forma multidimensional, implícita, focado em uma única dimensão ou não é utilizado para justificá-las? (FIGURA 3)

Figura 3 - Perspectiva de Desenvolvimento

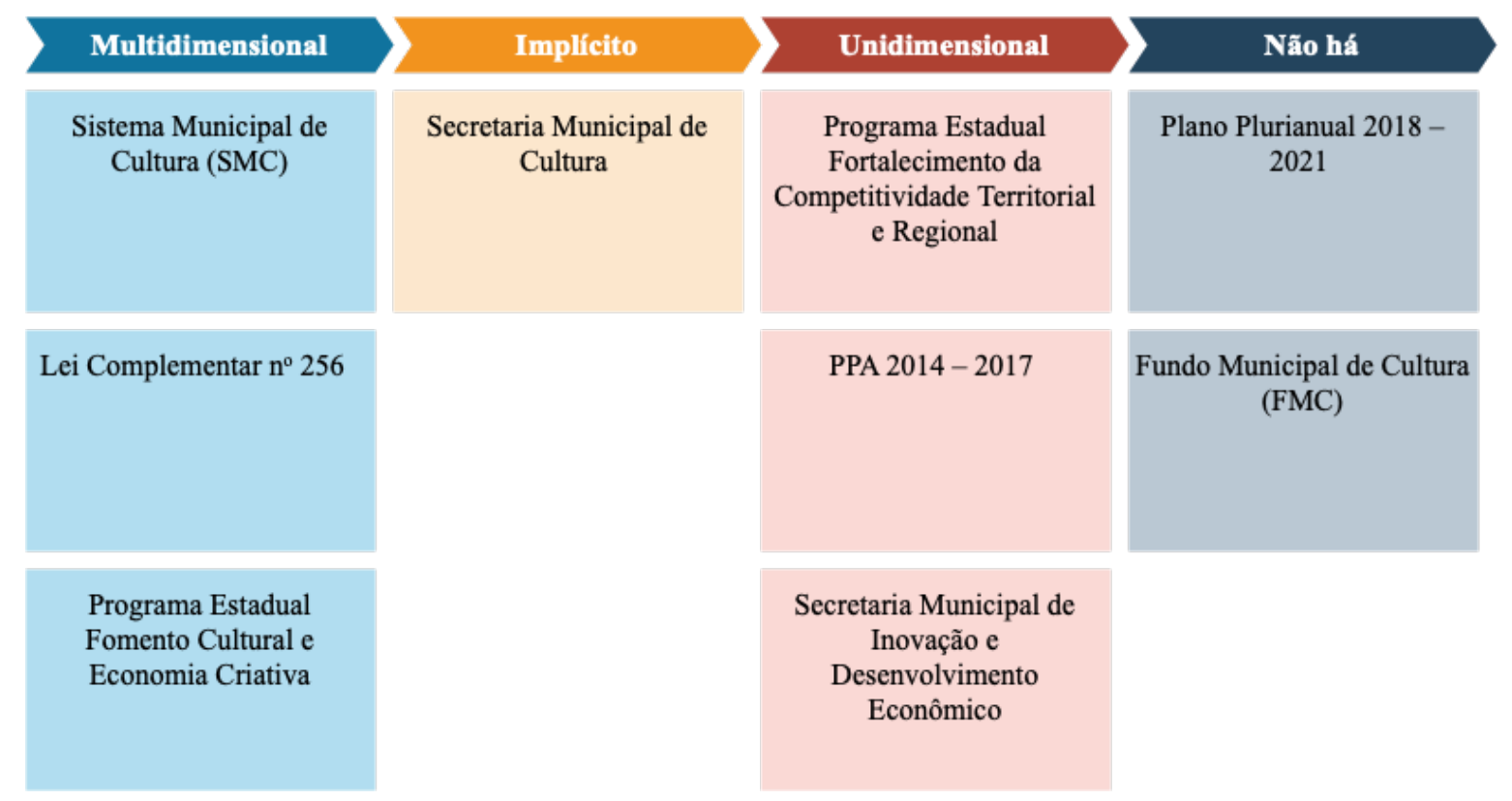

Fonte: Elaborado pelos autores com base nos dados São José dos Campos (2003, 2013a, 2013b, 2016, 2017a, 2017b) e São Paulo (2015).

Uma perspectiva multidimensional de desenvolvimento aparece explicita nos seguintes documentos: sistema municipal de cultura, lei complementar $n^{\circ} 256$ de 10 de julho de 2003 e o programa estadual fomento cultural e economia criativa, conforme segue.

Segundo a Lei no 9.343, de 26 de abril de 2016, o sistema municipal de cultura de São José dos Campos tem por finalidade promover o desenvolvimento humano, social e econômico, por meio do pleno exercício dos direitos culturais (SÃO JOSÉ DOS CAMPOS, 2016). Ainda, tal documento informa que a cultura é um direito fundamental do ser humano e deve ser "considerada importante vetor de desenvolvimento humano, social e econômico, devendo ser tratada pelo Poder Público Municipal como uma área estratégica para o desenvolvimento sustentável no Município ..." (SÃO JOSÉ DOS CAMPOS, 2016, p. 1). A multidimensionalidade é reafirmada quando a lei apresenta a economia da cultura como um "elemento estratégico da economia contemporânea, em que se configura como um dos segmentos mais dinâmicos e importante fator de desenvolvimento econômico e social" (SÃO JOSÉ DOS CAMPOS, 2016, p. 4). 
De forma mais específica, a lei complementar $\mathrm{n}^{0256}$ de 10 de julho de 2003, que estabeleceu uma alíquota de 2\% de ISSQN para atividades de grande interesse do município, algumas delas enquadradas como economia criativa, fez menção ao desenvolvimento em disposições gerais, “... poderá, através de iniciativa legal, conceder benefícios específicos para projetos de grande interesse para o desenvolvimento econômico e social do município ..." (SÃO JOSÉ DOS CAMPOS, 2003, p. 5). A nível estadual, o programa fomento cultural e economia criativa, ligado a Secretaria da Cultura do Estado de São Paulo, objetivava "fomentar o protagonismo dos agentes e das atividades socioeconômicas de base cultural ..." (SÃO PAULO, 2015, vol. 2, p. 88); tinha como produtos o fomento cultural por renúncia fiscal, tais como: PROAC ICMS, PROAC editais, dentre outros.

Nestes documentos, encontramos indícios de que uma perspectiva multidimensional de desenvolvimento estaria informando as políticas de cultura do município. Havendo um reforço no foco sobre desenvolvimento socioeconômico, influenciado pelos discursos de agências governamentais promotoras da temática (BRASIL, 2012; UNCTAD, 2010); deixando evidente também, além da importância econômica, o retorno para a sociedade por meio do investimento em cultura.

O desenvolvimento foi trazido na sua forma implícita pela Secretaria Municipal de Cultura quando da apresentação das atribuições da Fundação Cultural Cassiano Ricardo (FCCR)4, "promover o planejamento e fomento das atividades culturais com uma visão ampla e integrada no território do município, considerando a cultura como uma área estratégica para o desenvolvimento local" (SÃO JOSÉ DOS CAMPOS, 2016, p. 7). Isto é, não foi especificado qual área desenvolver, invocando o termo de forma implícita em sua multidimensionalidade.

O foco na dimensão econômica prevaleceu nas seguintes normas: programa estadual fortalecimento da competitividade territorial e regional, PPA 2014 - 2017 e na secretaria municipal de inovação e desenvolvimento econômico, conforme ilustrado.

O programa estadual fortalecimento da competitividade territorial e regional apresentou como objetivo "induzir o desenvolvimento econômico do Estado, com base na articulação dos agentes produtivos, na coordenação dos instrumentos de apoio e no fomento ao desenvolvimento das potencialidades regionais" (SÃO PAULO, 2015, vol. 2, p. 66).

Ao analisar os programas pertencentes à secretaria de inovação e desenvolvimento econômico nos Demonstrativo de Programas e Ações por Órgão e Unidade - Físico-Financeiro do PPA 2014 2017 de São José dos Campos, dois programas deram um norte quanto ao entendimento da perspectiva de desenvolvimento. Um visava à atração e manutenção de empresas e investimentos, cujo objetivo consistia na promoção de mecanismos que viabilizem a instalação de empresas no município, justificado pelo crescimento econômico sustentável e geração de emprego e renda. E outro programa, que mais se aproximou da economia criativa, denominado economia solidária 5, 6, como justificativa trouxe também a viabilização da geração de trabalho e renda por meio do cooperativismo (SÃO JOSÉ DOS CAMPOS, 2013a). Já a secretaria municipal de inovação e desenvolvimento econômico tem por competência "planejar, programar e executar a política de desenvolvimento econômico do município" (SÃO JOSÉ DOS CAMPOS, 2017a, p. 29).

Estas normas expuseram o viés econômico do tipo de desenvolvimento almejado pelas iniciativas. Apesar de também terem citado o desenvolvimento de potencialidades locais, todas deixaram bem clara a tendência econômica, sem menção a qualquer multidimensionalidade de desenvolvimento,

\footnotetext{
4 A Fundação Cassiano Ricardo (FCCR) é instituição cultural destinada à pesquisa e à difusão artística e literária, com responsabilidade jurídica própria e autonomia administrativa.

5 O programa economia solidária tinha por objetivo capacitar e organizar grupos que sejam solidários e economicamente sustentáveis, valorizando o mercado local.

6 Apesar de entendermos que a economia criativa e economia solidária são conceitualmente diferentes, ambas podem ser enquadradas como alternativas a "economia tradicional" e sua imbricação reside no fato que seus conceitos preconizam o desenvolvimento endógeno, o que permitiu fazer uma aproximação para a análise.
} 
sendo o ganho para sociedade o emprego/trabalho gerado e a renda advinda deste. Isto é, revelando maior preocupação econômica em comparação a outros tipos de desenvolvimento.

Por fim, alguns documentos não mencionaram o desenvolvimento em nenhuma forma, sendo eles: o plano plurianual 2018 - 2021 e o fundo municipal de cultura.

O plano plurianual de São José dos Campos, de 2018 - 2021, instituído pela Lei no 9.632 de 15 de dezembro de 2017, não trouxe mensagem de abertura, não foram apresentados os eixos estratégicos nos quais se desdobrariam os objetivos, justificativas e planos de ação para o atingimento das metas, logo, não foi possível estabelecer nenhuma relação com o desenvolvimento (SÃO JOSÉ DOS CAMPOS, 2017b). Do mesmo modo, o fundo municipal de cultura (FMC) apesar de contemplar o financiamento de projetos em diversas áreas da economia criativa, tais como artes visuais, teatro, música, patrimônio histórico e cultural, dentre outros, não justificou ou relacionou sua instituição a nenhuma forma de desenvolvimento propiciada por meio de investimentos em cultura (SÃO JOSÉ DOS CAMPOS 2013a).

\section{Endogeneidade}

Neste ponto analisaremos os fatores estruturantes à luz da categoria endogeneidade, desmembrada nas dimensões inter-relacionadas: participação, normatividade e transparência (FIGURA 4).

Figura 4 - Endogeneidade

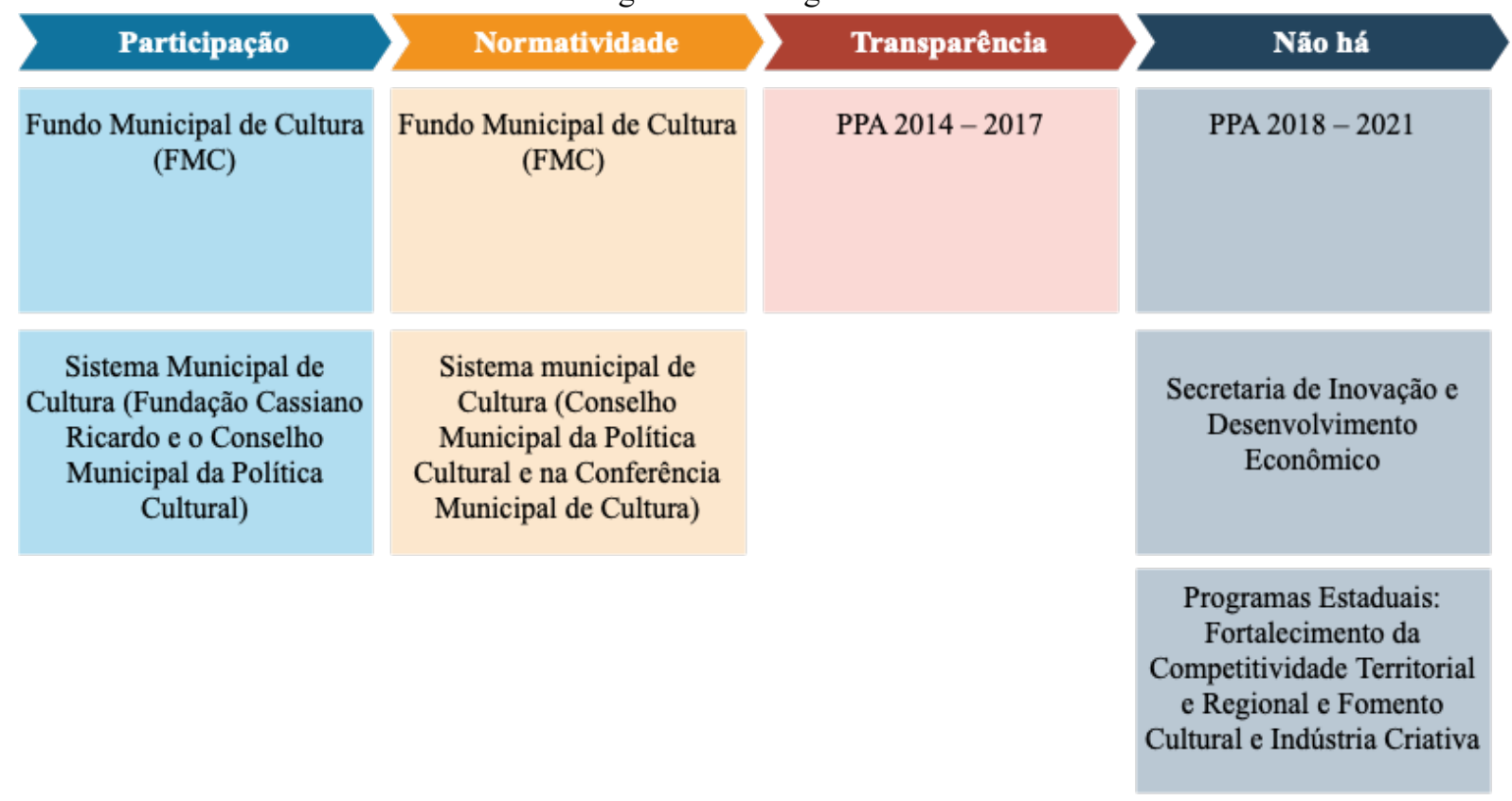

Fonte: Elaborado pelos autores com base nos dados São José dos Campos (2003, 2013a, 2013b, 2016, 2017b) e São Paulo (2015).

A participação pôde ser encontrada no fundo municipal de cultura, sistema municipal de cultura, fazendo parte deste a Fundação Cassiano Ricardo e, o Conselho Municipal da Política Cultural, conforme segue.

O Fundo Municipal de Cultura, instituído pela lei no 9.069 de 13 de dezembro de 2013, é gerido por um conselho que tem por atribuição orientar, administrar e fiscalizar os recursos existentes. Tal lei ainda apontou a participação de seis membros, sendo eles: Diretor Presidente da Fundação Cultural Cassiano Ricardo (FCCR), dois membros indicados pelo poder executivo e três membros da sociedade civil, indicados pelo Conselho Deliberativo da FCCR (SÃO JOSÉ DOS CAMPOS, 2013b). 
Da mesma maneira, na lei que apresenta a estrutura do Sistema Municipal de Cultura afirma-se que este seria o "principal articulador, no âmbito municipal, das políticas de cultura, estabelecendo mecanismos de gestão compartilhada com os demais entes federados e a sociedade civil" (SÃO JOSÉ DOS CAMPOS, 2016, p. 1). Além disso, menciona que é "de responsabilidade do Poder Público Municipal, com a participação da sociedade, planejar e fomentar políticas públicas de cultura ..." (SÃO JOSÉ DOS CAMPOS, 2016, p. 1).

Complementarmente, o Sistema Municipal de Cultura teria por objetivo "estabelecer um processo democrático de participação na gestão das políticas e dos recursos públicos na área cultural" (SÃO JOSÉ DOS CAMPOS, 2016, p. 5). Ademais, indicou como integrantes do SMC, a Fundação Cultural Cassiano Ricardo, com encargo de coordenação; as instâncias de articulação, pactuação e deliberação: Conselho Municipal de Política Cultural, Conselho Municipal do Patrimônio Histórico, Artístico e Cultural. Como mecanismos permanentes de consulta: Fórum Municipal de Cultura e Conferência Municipal de Cultura. Os instrumentos de gestão: Plano Municipal de Cultura, Sistema Municipal de Financiamento à Cultura, Sistema Municipal de Indicadores Culturais, Programa Municipal de Formação e Capacitação da Área da Cultura; e os sistemas setoriais da cultura: Sistema Municipal do Patrimônio Histórico, Sistema Municipal de Museus, Sistema Municipal de Arquivos Públicos, Sistema Municipal de Bibliotecas, Livro, Leitura e Literatura, Sistema Municipal de Arte e Sistema Municipal de Manifestações Culturais.

A partir desta estrutura, foram apontadas as atribuições de cada bloco pertencente ao SMC, a Fundação Cultural Cassiano Ricardo ficaria incumbida de "formular e implementar, com a participação da sociedade civil, o plano municipal de cultura, executando as políticas e as ações culturais definidas" (SÃO JOSÉ DOS CAMPOS, 2016, p. 7). Já o conselho municipal da política cultural (CMPC), contido nas instâncias de articulação, pactuação e deliberação:

é um órgão colegiado, consultivo, deliberativo, com composição paritária entre Poder Público e Sociedade Civil, esta com, no mínimo, 50\% de representantes, se constituiu no principal espaço de participação social institucionalizada, de caráter permanente ... (SÃO JOSÉ DOS CAMPOS, 2016, p. 8).

Ainda sobre a participação, a conferência municipal de cultura foi constituída para ser uma “instância de participação social, em que ocorre a articulação entre o Poder Público Municipal e a sociedade civil, por meio de organizações culturais e segmentos sociais, para analisar a conjuntura da área cultural no Município ..." (SÃO JOSÉ DOS CAMPOS, 2016, p. 9). Da mesma forma, foi definido que o plano municipal de cultura deveria ser elaborado por meio de "realização de audiências públicas, encontros e debates setoriais, realizados de forma democrática, garantindo-se a ampla participação da sociedade civil” (SÃO JOSÉ DOS CAMPOS, 2016, p. 10).

A partir destes dados, verificou-se que a administração local atentou para a prática da participação, pois foram identificados espaços de concertação variados compostos de uma diversidade de atores. Agora resta averiguar se essa heterogeneidade teria capacidade para protagonizar a tomada de decisão; faremos esta aproximação por meio da dimensão da normatividade.

A normatividade ficou evidente, no fundo municipal de cultura e no sistema municipal de cultura, mesmo que de forma obscura; e mais inteligível, no conselho municipal da política cultural e na conferência municipal de cultura, ilustradas na sequência.

A despeito do discurso prevalecente sobre a participação da sociedade civil, no fundo municipal de cultura a normatividade não ficou clara. Isto é, além de vincular a escolha dos membros da sociedade civil a uma entidade pública, não informou se todos teriam direito a voto, também não explicitou as regras decisórias, ademais, não especificou se e onde as informações seriam publicizadas, prejudicando a transparência. De forma semelhante, o sistema municipal de cultura expressou de forma superficial a preocupação com esta subcategoria, definindo apenas que a "participação da sociedade nas decisões de política cultural deve ser efetivada por meio da criação, articulação de 
conselhos paritários, com os representantes da sociedade civil, democraticamente eleitos ..." (SÃO JOSÉ DOS CAMPOS, 2016, p. 3).

Já o CMPC e a conferência municipal de cultura foram as únicas instâncias que depreenderam normatividade em relação à participação. No primeiro, foi estabelecida a participação paritária entre Estado e sociedade civil, garantindo normativamente o protagonismo da decisão conjunta; já a conferência, determinou que a representação da sociedade civil seja de, no mínimo, dois terços dos delegados.

Embora existam muitas menções à normatividade nos documentos analisados, principalmente quanto ao envolvimento da sociedade civil na tomada de decisão, elas se mostraram superficiais. Isso porque não foram especificadas a forma de eleição dos membros, e quando o fizeram vincularam sua escolha ao Estado.

E, por fim, a transparência, ou seja, os meios destinados à garantir que os cidadãos tenham acesso à regras elaboradas e às decisões tomadas, surgiu apenas no programa Modernização da Administração Pública do PPA 2014 - 2017. A alusão foi feita quando destacou a necessidade de "propiciar maior transparência nas ações do governo e dar qualidade, eficiência e resolutividade ao atendimento das demandas dos cidadãos e promover a eficiência na utilização dos recursos públicos" (SÃO JOSÉ DOS CAMPOS, 2013a, Anexo 2, p. 10). Entretanto, não foram identificados os meios pelos quais as informações seriam disponibilizadas para que a população pudesse participar e acompanhar a gestão pública, prejudicando a endogeneidade como um todo.

Não foi encontrada nenhuma subcategoria da endogeneidade no PPA 2018 - 2021, na secretaria de inovação e desenvolvimento econômico e nos programas que abrangeram a economia criativa do governo do Estado de São Paulo. A inviabilização da análise é uma consequência da baixa relevância que a transparência recebeu nos documentos analisados.

\section{Panorama do município de São José dos Campos}

O município de São José dos Campos, segundo o Índice de Cidades Criativas, exibiria nível médio de criatividade. Isso significa que teria potencial para atrair empresas da indústria criativa e que deveria investir em políticas públicas para catalisar os setores envolvidos. Interessante notar que, de fato, na análise realizada não encontramos um direcionamento persistente para esta indústria. Como vimos, o foco na economia criativa apareceu somente na lei que instituiu a Secretaria Municipal de Inovação e Desenvolvimento Econômico, sob responsabilidade do Departamento de Programas Estratégicos. Nos outros documentos analisados, encontramos direcionamento para setores específicos, como os ligados à cultura; demonstrando que os esforços estatais para estruturar essa indústria foram insuficientes para garantir a eficácia do funcionamento e expansão desse tipo de política pública. Isto é, os fatores estruturantes encontrados no município não foram criados especificamente para alavancar a economia criativa e isto comprometeu seu espraiamento.

Em relação à promoção do desenvolvimento multidimensional e a endogeneização (FIGURA 5), as políticas produzidas por São José dos Campos se caracterizaram por campos de ação voltados, principalmente, ao crescimento econômico. Mesmo que uma perspectiva multidimensional tenha surgido entre os dados, percebeu-se a prevalência da dimensão econômica, já que a maioria das políticas envolviam a atração e manutenção de empresas e investimentos, geração de emprego e renda, e também a inovação como impulsionadora do crescimento econômico, com dotações orçamentárias contemplando o parque tecnológico e o programa Inova São José, sendo P\&D consideradas atividades importantes para o desenvolvimento econômico local.

A participação foi mobilizada na maioria das normas, os espaços de concertação foram variados e contavam com a pluralidade de atores sociais. Averiguou-se a prevalência da participação paritária entre os órgãos da Administração Direta e a sociedade civil, como visto no sistema municipal de cultura e no conselho municipal da política cultural. Por vezes, viu-se até a predominância de membros não estatais, como no fundo municipal de cultura onde os atores sociais correspondiam mais da metade do total. 
Contudo, constatou-se fragilidade na previsão de meios para que aquela heterogeneidade pudesse se manifestar nos processos decisórios. Afora o recorrente discurso da participação paritária, e até mesmo predominância da sociedade civil nas decisões, não foram encontradas normatividades suficientes que respaldassem tal discurso. Apenas o conselho municipal da política cultural e a conferência municipal de cultura garantiram, por meio da normatividade, o protagonismo da decisão conjunta.

A transparência foi explicitada em apenas um programa contido no PPA 2014-2017, os demais documentos não mencionavam qualquer preocupação com a publicização de informação dos planos, comitês, conselhos e etc. Disso decorre prejuízo ao acesso à informação sobre o que está sendo discutido e implementado no estado e no município, bem como debilita o caráter endógenos da política, impossibilitando que os interesses e demandas da sociedade influenciem o Estado.

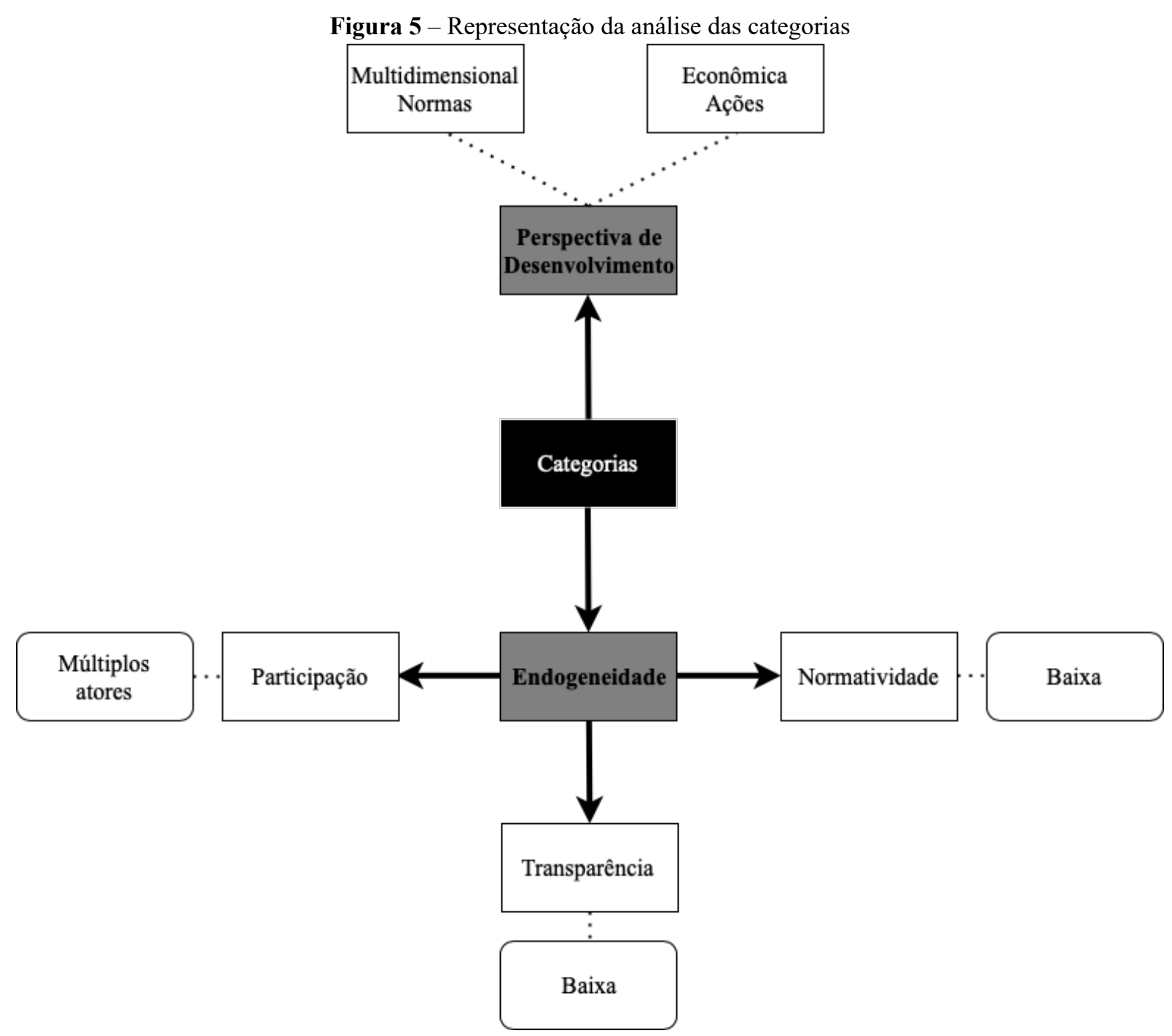

Fonte: Elaborado pelos autores.

Enfim, percebeu-se que embora a política conte com elementos de caráter endógeno, esses exibem fragilidades. Tal conformação pode comprometer a perspectiva de desenvolvimento manifestada nas inciativas. Sobre isso, evidenciou-se nas ações uma visão unidimensional, no sentido de que valoriza um aspecto promotor do desenvolvimento: o crescimento econômico. Verificou-se que a promoção da economia criativa foi inserida na política econômica já existente do município. Essa tática de endogeneização promoveu a apropriação do conceito de forma a adaptá-lo às estruturas existentes. Cabe 
investigar como tal recorte se combina com a aproximação ao setor cultural, marcado pelo imbricamento multidimensional. Se por um lado a perspectiva de desenvolvimento, encontrada nas ações, é unidimensional, as estruturas de governança preveem o envolvimento de atores plurais, vinculados a um setor que extrapola as fronteiras entre econômico e social. Nesse sentido, verifica-se algum grau de debilidade no desenho da política.

\section{CONSIDERAÇÕES FINAIS}

O artigo teve por objetivo analisar o desenho da política pública de economia criativa para identificar a perspectiva de desenvolvimento que a embasa bem como a forma de endogeneização do conceito em relação ao contexto local. Para tanto, foi utilizado um esquema analítico que permitiu investigar, por meio de suas categorias, se as políticas de economia criativa em foco são modeladas de forma a incorporar as características locais e direcionar-se para o desenvolvimento da comunidade.

A abordagem proposta auxiliou na compreensão do desenvolvimento enquanto mudança social desejada, permitindo conectá-la às políticas públicas de economia criativa, uma vez que estas conformariam meios para produzir tal mudança, pressupondo que o desenvolvimento é um objetivo que pode ser perseguido por meio de ações deliberadas. Contudo, a escolha e o desenho desses instrumentos e instituições não são processos neutros, sofrendo influência também da cultura local e das ideologias dominantes.

Nesse sentido, desenhar políticas públicas em consonância as peculiaridades locais, possibilitadas por meio da promoção do desenvolvimento multidimensional, da participação de múltiplos atores, de regras que garantem a tomada de decisão de forma coletiva e da transparência, asseguraria sua robustez, por conseguinte, sua eficácia. A robustez é entendida como a "capacidade das políticas de persistir ao longo do tempo, superando choques externos e perturbações internas relevantes" (CAPANO; WOO, 2017, p. 2, tradução nossa). Como uma estrutura conceitual, pode permitir a concepção de decisões políticas, planos e estratégias viáveis que são "insensíveis" às incertezas (BANKES, 2010).

Ao assumir que o desenho de políticas é aquela atividade baseada em conhecimento e informação por meio da qual, em um contexto específico, os formuladores de políticas e as partes interessadas tentam formular soluções para problemas percebidos como coletivos (HOWLETT, 2011), é bastante relevante para avaliar se e como a robustez, propiciada pela adaptabilidade da política ao contexto local, acessada aqui por meio do modelo analítico, deve ser realmente levada em consideração pelos estudiosos de políticas e, assim, fazer parte do panorama dos tomadores de decisão.

Assim sendo, pudemos constatar que as políticas públicas de economia criativa em São José dos Campos refletem moderadamente as características do território, visto que apesar da perspectiva multidimensional de desenvolvimento tenha surgido, percebeu-se que a própria estrutura municipal responsável estava voltada à promoção do crescimento econômico. Consequentemente, grande parte das normas, que compunham o desenho da política, envolviam a atração e manutenção de empresas e investimentos, geração de emprego e renda, e também a inovação como impulsionadora do crescimento econômico, com dotações orçamentárias contemplando o parque tecnológico e o programa Inova São José, sendo P\&D consideradas atividades importantes para o desenvolvimento econômico local. Sendo assim, observamos que houve uma adaptação ao contexto local já que o município buscou incorporar ao desenho da política pública sua vocação como polo tecnológico para inovação, P\&D e etc. Contudo, a promoção de desenvolvimento multidimensional ficou comprometida, sendo apenas o discurso constante em algumas normas. Além disso, se por um lado encontramos uma pluralidade de atores, por outro não identificamos as formas de manifestação da heterogeneidade nas decisões, aliado a isso, a ausência de transparência reforça essa dinâmica.

Com isso, buscou-se contribuir para a produção de informações sobre o desenho de políticas que manejam conceitos delineados em contextos internacionais e que pretendem utilizá-los como base para a promoção de mudanças sociais locais. Ampliar o conhecimento sobre a estrutura das políticas, 
os conceitos que as embasam e as formas com que são traduzidos em dinâmicas organizacionais pode colaborar para o incremento dos processos de desenho e, assim, para a produção de resultados superiores para a sociedade.

Cabe apontar algumas limitações do esquema de análise empregado: (a) a base teórica foi desenvolvida a partir da perspectiva dos países da América Latina e da Europa com desenvolvimento tardio, que pode não se enquadrar na análise de experiências de países com capitalismo avançado; (b) a amplitude das categorias pretende ser inclusiva em termos de setores de políticas públicas; no entanto, é relevante observar se isso é confirmado na aplicação [ou não]; (c) as categorias analíticas podem ser mais abrangentes do que os objetivos da pesquisa, o que pode levar à necessidade de adaptações; e, (d) o objeto do modelo é o desenho das políticas, isto é, o conteúdo das políticas, deixando em segundo plano os processos de sua formulação. Essas questões, e outras que surgirão da manipulação do modelo, podem ser vistas como espaços de criatividade, nos quais o pesquisador sempre pode se mover guiado pelo problema de pesquisa. No mais, entendemos que todo conhecimento é transitório e deve ser continuamente trabalhado, criticado e desenvolvido.

Por fim, com base nos resultados, é possível sugerir alguns pontos para o desenvolvimento de pesquisas futuras, entre os quais: investigações acerca de dois municípios de diferentes e de mesmo nível de criatividade; comparativo entre municípios que aparecem no ranking e outros que não, entre estados ou países, como forma de confirmar se a abordagem criada assegura a indubitabilidade da análise e da interpretação do desenho de políticas públicas de economia criativa. E, principalmente, analisar as políticas públicas que estão em funcionamento para verificar em que medida as orientações contidas no desenho da política se manifestam nos processos de implementação. 


\section{Referências}

ALBUQUERQUE, F.; ZAPATA, T. A importância da estratégia de desenvolvimento local/territorial no Brasil. In: DOWBOR, L.; POCHMANN, M. (Orgs.). Políticas para o desenvolvimento local. São Paulo: Fundação Perseu Abramo, 2010. p. 211-225,

BANKES, S. Robustness, adaptivity, and resiliency analysis. In: Symposium of the Association for the Advancement of Artificial Intelligence. 2010. Anais [...]. Arlington, VA, USA. <http://www.aaai.org/ocs/index.php/FSS/FSS10/paper/ view/2242/2643>

BARDIN, L. Análise de conteúdo. Lisboa: Edições 70, 2007.

BOISIER, S. ¿Hay espacio para el desarrollo local en la globalización? Revista de la Comisión Económica para América Latina y el Caribe (CEPAL), n. 86, p. 47-62, 2005.

BRASIL. Ministério da Cultura. Plano da Secretaria da Economia Criativa: Políticas, Diretrizes e Ações, 2011 2014. Brasília, DF: Ministério da Cultura, 2012.

BRASIL. O que é PPA?. 2018. Disponível em: <https://bit.ly/2QO5peZ>

BUARQUE, S. C. Construindo o desenvolvimento local sustentável: metodologia de planejamento. Brasília, DF: IICA, 1999.

CAPANO, G.; WOO, J. J. Resilience and robustness in policy design: a critical appraisal. Policy Sciences, v. 50, p. 399426, 2017.

CHINDARKAR, N.; HOWLETT, M.; RAMESH, M. Introduction to the Special Issue: Conceptualizing Effective Social Policy Design: Design Spaces and Capacity Challenges. Public Administration and Development, v. 37, n. 1, p. 3-14, 2017.

COELHO, F. D. Desenvolvimento Econômico Local no Brasil: as experiências recentes num contexto de descentralização. Revista de la Comisión Económica para América Latina y el Caribe (CEPAL), 2000.

COLEBATCH, H. K. The Idea of Policy Design: Intention, Process, Outcome, Meaning and Validity. Public Policy and Administration, v. 33, n. 4, p. 365-383, 2018.

COMPTON, M. E.; LUETJENS, J.; HART, P. Designing for Policy Success. International Review of Public Policy, v. 1, n. 1-2, p. 119-146, 2019.

DAGNINO, E. (Ed.). Sociedade civil e espaços públicos no Brasil. São Paulo: Brasiliense, 2002.

DEPARTMENT OF CULTURE, MEDIA AND SPORT (DCMS). The creative industries mapping document. London: HMSO, 2001.

DOCAMPO, M. G. El desarrollo local en el marco de los procesos de globalización. In: Perspectivas teóricas en Desarrollo Local. La Coruna: Netbiblo, 2007, p. 1-37.

FEDERAÇÃO DAS INDÚSTRIAS DO ESTADO DO RIO DE JANEIRO (FIRJAN). Mapeamento da Indústria Criativa no Brasil. Rio de Janeiro, RJ: FIRJAN, $2016 \mathrm{a}$.

FEDERAÇÃO DAS INDÚSTRIAS DO ESTADO DO RIO DE JANEIRO (FIRJAN). Consulta ao Índice sobre Economia Criativa. Rio de Janeiro, RJ: FIRJAN, 2016b.

FEDERAÇÃO DAS INDÚSTRIAS DO ESTADO DO RIO DE JANEIRO (FIRJAN). Indústria Criativa: Análise Especial: São Paulo. Rio de Janeiro, RJ: FIRJAN, 2016c. Disponivel em: <https://bit.ly/3cGmXlE>

FEDERAÇÃO DO COMÉRCIO DE SÃO PAULO (FECOMÉRCIO). Índice de Criatividade das Cidades, 2012. Disponível em: $<$ https://bit.ly/2KE9rCQ $>$. 
HEIDEMANN, F. G. Do sonho do progresso às políticas de desenvolvimento. In: HEIDEMANN, F. G.; SALM, J. F. (Eds.). Políticas Públicas e Desenvolvimento: bases epistemológicas e modelos de análise. Brasília: UNB, 2014, p. 21-49.

HOWLETT, M. Designing public policies. London: Routledge, 2011.

HOWLETT, M. Challenges in applying design thinking to public policy: dealing with the varieties of policy formulation and their vicissitudes. Policy \& Politics, v. 48, n. 1, 49-65, 2020.

HOWLETT, M.; MUKHERJEE, I. Policy Design: From tools to toolpaths. Canadian Public Administration, v. 60, n. 1, p. 140-144, 2017.

HOWLETT, M.; MUKHERJEE, I. The Contribution of Comparative Policy Analysis to Policy Design: Articulating Principles of Effectiveness and Clarifying Design Spaces. Journal of Comparative Policy Analysis: Research and Practice, v. 20, n. 1, p. 72-87, 2018.

HOWLETT, M.; MUKHERJEE, I; WOO, J. J. From Tools to Toolkits in Policy Design Studies: The New Design Orientation towards Policy Formulation Research. Policy \& Politics, v. 43, n. 2, p. 291-311, 2015.

INSTITUTO BRASILEIRO DE GEOGRAFIA E ESTÁTISTICA (IBGE). Cidades. Disponível em: < http://cidades. ibge.gov.br/xtras/home.php>.

INGLEHART, R.; WELZEL, C. Modernização, mudança cultural e democracia: a sequência do desenvolvimento humano. São Paulo: Francis, 2009.

LAVALLE, A. G.; VOIGT, J.; SERAFIM. O que fazem os conselhos e quando o fazem? Padrões decisórios e o debate dos efeitos das instituições participativas. Dados-Revista de Ciências Sociais, v. 59, n. 3, p. 609-650, 2016.

LIMA, L. L.; D’ASCENZI, L. Governando com Políticas Públicas: análise do desenho das políticas de desenvolvimento em Belo Horizonte, Fortaleza e Porto Alegre. In: MARENCO, A.; NOLL, M. I. (Orgs.). A política, as políticas e os controles: Como são governadas as cidades brasileiras. 1. ed. Porto Alegre, RS: Tomo Editorial, 2018.

LINDER, S. H.; PETERS, B. G. Research Perspectives on the Design of Public Policy: Implementation, Formulation, and Design. In: PALUMBO, D. J.; CALISTA, D. J. (Eds.). Implementation and the Policy Process: Opening up the Black Box. Westport: Greenwood Press, 1990, p. 51-66.

MARTINS JÚNIOR, W. P. Transparência administrativa: publicidade, motivação e participação popular. 2 . ed. São Paulo, SP: Saraiva, 2010.

OHLWEILER, L. A construção e implementação de políticas públicas: desafios do Direito administrativo moderno. Verba Juris, v. 6, n. 6, p. 269-300, 2007.

OLIVEIRA, J. M.; ARAÚJO, B. C.; SILVA, L. V. Panorama da economia criativa no Brasil. Rio de Janeiro: IPEA (Texto para Discussão, n. 1880), 2013.

PETERS, B. G. Designing Institutions for Designing Policy. Policy \& Politics, v. 48, n. 1, p. 131-47, 2020.

PLATT NETO, O. A.; CRUZ, F.; ENSSLIN, S.; ENSSLIN, L. Publicidade e Transparência das Contas Públicas: obrigatoriedade e abrangência desses princípios na administração pública brasileira. Contabilidade Vista \& Revista, v. 18, n. 1, p. 75-94, 2007.

PORTO ALEGRE. Porto Alegre Criativa: Plano Municipal de Economia Criativa - Diretrizes. 2014. Disponível em: $<$ http://bit.ly/2QjSL86>

REIS, A. C. F. Introdução. In: REIS, A. C. F. (Org.). Economia Criativa como estratégia de desenvolvimento: uma visão dos países em desenvolvimento. São Paulo: Itaú Cultural, 2008, p. 14-49.

SÃO JOSÉ DOS CAMPOS. Lei Complementar no 256, de 10 de Julho de 2003. Altera alíquotas do Imposto Sobre Serviços de Qualquer Natureza - ISSQN, dispõe sobre a concessão de incentivos fiscais a empresas, e dá outras providências. 2003. Disponível em: <http://bit.ly/376Vt6u> 
SÃO JOSÉ DOS CAMPOS. Lei no 9.070, de 16 de Dezembro de 2013. Dispõe sobre o Plano Plurianual para o período de 2014 a 2017. 2013a. Disponível em: <http://bit.ly/2pjHNEr>

SÃO JOSÉ DOS CAMPOS. Lei no 9.069, de 13 de dezembro de 2013. Institui o Fundo Municipal de Cultura de São José dos Campos, vinculado à Fundação Cultural Cassiano Ricardo, e dá outras providências. 2013b. Disponível em: $<$ http://bit.ly/2CJU340>

SÃO JOSÉ DOS CAMPOS. Lei no 9.343, de 26 de abril de 2016. Institui o Sistema Municipal de Cultura de São José dos Campos, e dá ouras providências. 2016. Disponível em: <https://bit.ly/3bGLCq1>

SÃO JOSÉ DOS CAMPOS. Lei $\mathbf{n}^{\mathbf{0}} \mathbf{9 . 5 6 0}$, de 13 de Julho de 2017. Altera a Lei no 9495 , de que modifica a redação da Lei no 3.939, de 21 de março de 1991, que "Dispõe sobre a Estrutura Administrativa da Prefeitura Municipal de São José dos Campos". 2017a. Disponível em: <https://bit.ly/2Y7VNAa>

SÃO JOSÉ DOS CAMPOS. Lei no 9.632, de 15 de Dezembro de 2017. Dispõe sobre o Plano Plurianual para o período de 2018 a 2021. 2017b. Disponível em: <http://bit.ly/376cBtp>

SÃO PAULO (MUNICÍPIO). Lei no 16.050, de 31 de julho de 2014. Aprova a Política de Desenvolvimento Urbano e o Plano Diretor Estratégico do Município de São Paulo e revoga a Lei no 13.430/2002. 2014. Diário Oficial [da] Cidade de São Paulo, São Paulo, SP, 59 (140) - Suplemento - 3, 1 ago. 2014.

SÃO PAULO (ESTADO). Secretaria de Planejamento e Gestão. Lei no 16.092, de 20 de Dezembro de 2015. Plano Plurianual 2016 - 2019. 2015. Disonível em: <http://bit.ly/2Qi1NlR>

SEN, A. Temas-chave do século XXI. In: SEN, A.; KLIKSBERG, B. As pessoas em primeiro lugar: a ética do desenvolvimento e os problemas do mundo globalizado. São Paulo: Companhia das Letras, 2010. p. 15-136.

TAPIA, J. R. B. Desenvolvimento local, concertação social e governança: a experiência dos pactos territoriais na Itália. São Paulo em Perspectiva, v. 19, n. 1, p. 132-139, 2005.

TIRELLI, C. Conectando políticas públicas e território: a contribuição da perspectiva relacional. In: L. L. LIMA, L. L; SCHABBACH, L. M. (Orgs.). Políticas Públicas: questões teórico-metodológicas emergentes. Porto Alegre: UFRGS/CEGOV, 2020, p. 242-267.

UNITED NATIONS CONFERENCE ON TRADE AND DEVELOPMENT (UNCTAD). Creative Economy Report 2010 Creative Economy: A Feasible Development Option. New York: United Nations, 2010.

VÁZQUEZ BARQUERO, A. Desarrollo económico local y descentralización: Aproximación a un marco conceptual. Revista de la Comisión Económica para América Latina y el Caribe (CEPAL), 2000, p. 1-50.

VÁZQUEZ BARQUERO, A. Desenvolvimento endógeno em tempos de globalização. Porto Alegre: Fundação de Economia e Estatística, 2001.

VÁZQUEZ BARQUERO, A. Desarrollo endógeno. Teorías y políticas de desarrollo territorial. Investigaciones regionales, n. 11, p. 183-210, 2007.

VITTE, C. C. S. Gestão do desenvolvimento econômico local: algumas considerações. Revista Internacional de Desenvolvimento Local, v. 8, n. 13, p. 77-87, 2006. 
Histórico Recebido em: 20/08/2020

Aceito em: 20/09/2020

Concepção: RBA; LLL

Coleta de dados: RBA; LLL

Contribuição

Análise de dados: RBA; LLL

Elaboração do manuscrito: RBA; LLL

Revisões críticas de conteúdo intelectual importante: RBA; LLL

Aprovação final do manuscrito: RBA; LLL

Financiamento Conselho Nacional de Desenvolvimento Científico e Tecnológico (CNPq) 